\title{
Toxicity of glycerol for the stallion spermatozoa: Effects on membrane integrity and cytoskeleton, lipid peroxidation and mitochondrial membrane potential
}

B Macias Garcia, C Ortega Ferrusola, I M Aparicio, A Miro-Moran, A Morillo Rodriguez, J M Gallardo Bolanos, L Gonzalez Fernandez, C M Balao da Silva,

Heriberto Rodriguez-Martinez, J A Tapia and F J Pena

\section{Linköping University Post Print}

N.B.: When citing this work, cite the original article.

Original Publication:

B Macias Garcia, C Ortega Ferrusola, I M Aparicio, A Miro-Moran, A Morillo Rodriguez, J M Gallardo Bolanos, L Gonzalez Fernandez, C M Balao da Silva, Heriberto RodriguezMartinez, J A Tapia and F J Pena, Toxicity of glycerol for the stallion spermatozoa: Effects on membrane integrity and cytoskeleton, lipid peroxidation and mitochondrial membrane potential, 2012, Theriogenology, (77), 7, 1280-1289.

http://dx.doi.org/10.1016/j.theriogenology.2011.10.033

Copyright: Elsevier

http://www.elsevier.com/

Postprint available at: Linköping University Electronic Press

http://urn.kb.se/resolve?urn=urn:nbn:se:liu:diva-76799 


\title{
Toxicity of glycerol for the stallion spermatozoa: effects on membrane integrity and cytoskeleton, lipid peroxidation and mitochondrial membrane potential.
}

Macías García B, Ortega Ferrusola $\mathrm{C}^{2}$ Aparicio IM, ${ }^{2}$ Miró-Morán A, Morillo Rodriguez A, Gallardo Bolaños JM, ${ }^{2}$ González Fernández L, Balao da Silva CM, ${ }^{3}$ Rodríguez Martínez H, ${ }^{2}$ Tapia JA, Peña FJ*

Veterinary Teaching Hospital, Laboratory of Equine Reproduction, ${ }^{2}$ Department of Physiology Faculty of Veterinary Medicine, University of Extremadura Avd. de la Universidad s/n Cáceres Spain, ${ }^{3}$ Department of Clinical and Experimental Medicine Faculty of Health Sciences Linköping University, Linköping, Sweden

* Correspondence to Dr. FJ Peña Veterinary Teaching Hospital, Laboratory of Equine Reproduction, Faculty of Veterinary Medicine University of Extremadura Avd de la Universidad s/n 10003 Cáceres Spain. E-mail fjuanpvega@unex.es

\section{Acknowledgements}

The investigations of the authors received financial support from Ministerio de Ciencia e Innovación- FEDER Madrid, Spain Grants AGL 2010- 20758 (GAN), INIA RZ2008-0001800-00 and Junta de Extremadura FEDER GR 10010. The generous collaboration of the Service of Equine Breeding of the Spanish Army is acknowledged

\begin{abstract}
Glycerol is to date, the most widely used cryoprotectant to freeze stallion spermatozoa at concentrations ranging from 2 to $5 \%$. Cryoprotectant toxicity has been claimed to be the single most limiting factor for the success of cryopreservation. In order to evaluate the toxic effects of the concentrations of glycerol used in practice, stallion spermatozoa were incubated in BWW media supplemented with $0 \%, 1,5 \%, 2,5 \%, 3.5 \%$ and $5 \%$ glycerol. In two additional experiments a hyposmotic $(75 \mathrm{mOsm} / \mathrm{Kg})$ and a hyperosmotic $(900 \mathrm{mOsm} / \mathrm{Kg})$ control media were also included. Spermatozoa's parameters evaluated included, cell volume, membrane integrity, lipid peroxidation, caspase 3, 7 and 8 activation, mitochondrial membrane potential and cytoskeleton integrity. Glycerol exerted toxicity at concentrations equal or greater than $3,5 \%$ and the maximal toxicity was observed at $5 \%$. The actin cytoskeleton was especially sensitive to glycerol toxicity, since it induced rapid $\mathrm{F}$ actin depolymerization at concentrations over $1.5 \%$. The sperm membrane and the mitochondria were other structures affected. The toxicity of glycerol apparently is related to osmotic and non-osmotic effects. In view of our results the concentration of glycerol in the freezing media for the stallion spermatozoa should be no greater than $2.5 \%$.
\end{abstract}

Key words: stallion, sperm, glycerol, toxicity, cryopreservation 


\section{1.- INTRODUCTION}

The equine industry is experiencing an steadily increasing interest in reproductive technologies[1, 2]; among them sperm freezing is considered a specially interesting tool to increase the international commerce of semen, and or to preserve the genetics of superior stallions [3, 4]. In the near future, the probable introduction in the market of both refrigerated and frozen sexed sperm, stresses the need of further research in stallion sperm cryobiology. Is remarkable that procedures to freeze mammalian spermatozoa developed quasiempirically nearly 60 years ago are essentially used today[5-7]. Damage during cryopreservation occurs according to the two factors hypothesis[8], this theory states that cells cooled too rapidly are killed by intracellular ice formation, while cells cooled too slowly are killed by long exposure to concentrated solutions resulting from the progressive conversion of water to ice [9]. To avoid this later effect cell permeable cryoprotectants (CPA) are incorporated to freezing extenders. This kind of cryoprotectants such as glycerol, exerts their action retaining water within the cell, avoiding excessive dehydration due to the exposure to concentrated solutions. The higher their concentration the higher the protective effect[10]. On the other hand cryoprotectant toxicity has been claimed to be the single most limiting factor for the success of cryopreservation [11]. To freeze mammalian sperm glycerol is the most widely used cryoprotectant [12], however beside the cryoprotective action, glycerol may have toxic effects on the spermatozoa on a dose dependent manner. In the equine species semen is frozen using glycerol at concentrations ranging from 2 to $5 \%$ [4, 13-15], however very few controlled studies have addressed the toxicity of different concentrations of glycerol [16-18]. The efficacy of cryopreservative agents is almost always based on comparing the prefreeze sperm motility with the immediate post thaw motility, however this approach do not take into account damage that may have been caused by the intrinsic toxicity of the cryoprotectant. An ideal cryoprotector must penetrate the membrane, otherwise it will itself dehydrate the cell osmotically and stimulate freezing injury and, at the same time must be nontoxic at the concentrations necessary to prevent excessive dehydration. It is well accepted that permeating cryoprotectants do have toxic effects (as distinghised from osmotic effects)[19, 20], noteworthy has been pointed out that while cryoprotectant toxicity is well present in vitrification research, there is probably less awareness of the relevance of cryoprotectant toxicity on the part of those that use freezing as their method of cryopreservation [11]

Recent evidence[21] indicates that the main factor explaining cryoinjury in the equine species, is an osmotic imbalance at thawing. This fact stresses the importance of a rapid penetration at freezing and exit at thawing of the cryoprotective agent to minimize cryoinjury. In addition it has been proposed that damage after freezing and thawing in certain cases can be highly correlated with the concentration of permeating cryoprotectant during freezing and thawing [22], thus it may be necessary to increase our knowledge on cryoprotectant toxicity towards stallion spermatozoa to understand and significantly reduce freezing injury during cryopreservation. Thus the study of glycerol and its toxic effects on the stallion spermatozoa may open clues to improve current cryopreservation protocols. The aims of this study were to evaluate the intrinsic toxicity of glycerol separately from its osmotic effect to establish the toxicity of different concentrations of glycerol. The toxicity of osmotic nature was evaluated measuring changes in the cellular volume of the stallion spermatozoa. 


\section{2.- MATERIAL AND METHODS}

\section{1.- Semen collection}

Semen (four ejaculates per stallion) was obtained from 4 Pure Spanish Stallions (PRE) individually housed at the Veterinary Teaching Hospital of the University of Extremadura, Cáceres, Spain. The stallions were maintained according to institutional and European regulations, and were collected on a regular basis (two collections/week) during the 2010 breeding season. Ejaculates were collected using a Missouri model artificial vagina with an inline filter to separate the gel fraction, lubricated and pre-warmed to $45-50^{\circ} \mathrm{C}$. The collected ejaculate was immediately transported to the laboratory for evaluation and processing.

\section{2.- Semen Processing}

For each stallion aliquots of $500 \times 10^{6}$ total spermatozoa were centrifuged at $800 \mathrm{~g}$ for ten minutes at room temperature in $35 \%$ colloid (Puresperm $@$, Nidacom Mölndal Sweden) suspension in order to remove contaminating cells and debris. Seminal plasma was then discarded and the sperm pellet re-suspended to $100 \times 10^{6}$ sperm cells in Biggers Whitten and Whittingham (BWW) media (91.06 mM NaCl, $4.78 \mathrm{mM}$ KCL, $2.44 \mathrm{mM} \mathrm{Mg} \mathrm{SO}, 1.17 \mathrm{mM}$ KPO4, $21.0 \mathrm{~mm}$ HEPES, $5.5 \mathrm{mM}$ glucose (anhydrous), $0.25 \mathrm{mM}$ sodium pyruvate, $1.71 \mathrm{mM}$ lactic acid hemicalcium salt, and $21.55 \mathrm{mM}$ sodium lactate) at $320 \mathrm{mOsm} / \mathrm{Kg}$ and $\mathrm{pH}$ 7.4. All media were filtered through a $0.45 \mu \mathrm{m}$ filter. Aliquots of semen were extended in BWW media supplemented with $0 \%$ (control) $1,5 \%, 2,5 \%, 3,5 \%$ and $5 \%$ of glycerol. Samples were incubated for up to 60 minutes at $37^{\circ} \mathrm{C}$ and then aliquots were taken for cell volume measurement and flow cytometry analysis. The reasons to incubate at $37^{\circ} \mathrm{C}$ were to ensure the maximal permeability of the stallion spermatozoa to glycerol, and in this way can be minimized the osmotic shock and the intrinsic toxicity of glycerol can be better manifested, separating the osmotic effect from the intrinsic toxicity of glycerol[17], and since the major damage during cryopreservation is at thawing[21] the final temperature at which the spermatozoa are going to be exposed in the extender containing glycerol was chosen. In addition previous studies of glycerol toxicity in human spermatozoa have used this approach[23]. On the other hand is customary in the equine species to add glycerol at $22{ }^{\circ} \mathrm{C}$. The osmolarities of the media were respectively $320,388,492,670,750$ and $1300 \mathrm{mOsm} / \mathrm{Kg}$ for final concentrations of glycerol $0 \%, 1,5 \%, 2,5 \%, 3,5 \%$ and $5 \%$. All osmolarities were checked using a freeze point digital micro-osmometer Type 5 R (Hermann Roebling Messtechnik Berlin Germany)

\section{3.- Determination of Cellular Volume}

Cellular volume was measured using a Multisizer 3 Coulter Counter (Coulter Corporation Inc., Miami, FL, USA) calibrated according to the Beckman Coulter Particle Characterization assay sheet aperture Instrument Standard L5 for an aperture tube size of $50 \mu \mathrm{M}$ reference 6602794 and calibration verified using standards L3, L5 and L10 references 6602793, 6602794 and 6602797, following the instructions of the manufacturer. Spermatozoa were suspended in BWW media and drawn trough a cylindrical opening $(2-60 \mu \mathrm{m})$ separating two electrodes between which a small electrical current flows. As each particle passes through the aperture, displaces its own volume of conducting liquid, momentarily increasing the impedance of the aperture. This change produces a pulse that is digitally processed in real 
time and that is proportional to the tridimensional volume of the particle that produced it. The analysis of the pulses was digitally converted to volume $\left(\mu \mathrm{m}^{3}\right)$. For each sample, 30,000 events were analyzed and, if present, particles below 6 and above $60 \mu \mathrm{m}^{3}$ were discarded.

\section{4.- Assessment of subtle sperm membrane changes and viability}

Early sperm membrane changes and viability were determined as described in Peña et al.[24] with modifications for adaptation to the equine species $[25,26]$ In brief, one $\mathrm{mL}$ of sperm suspension $\left(5 \times 10^{6}\right.$ spermatozoa/mL) was loaded with $3 \mu \mathrm{L}$ of Yo-Pro-1 $(25 \mu \mathrm{M})$ and one $\mu \mathrm{L}$ of Ethidium Homodimer-1 (1.167 mM) (Molecular Probes Europe), which was -after thorough mixing- incubated at $37^{\circ} \mathrm{C}$ in the dark for $16 \mathrm{~min}$. This staining distinguishes four sperm subpopulations. The first is the subpopulation of unstained spermatozoa. These spermatozoa are considered alive and without any membrane alteration. Another sperm subpopulation consists of Yo-Pro-1 positive cells emitting green fluorescence. It is has been demonstrated that in the early stages of apoptosis there is a modification of membrane permeability that selectively allows entry of some non-permeable DNA-binding molecules [27]. This subpopulation groups spermatozoa which may show early damage or a shift to another physiological state, since membranes become slightly permeable during the first steps of injury, enabling Yo-Pro-1 but not ethidium homodimer to penetrate the plasma membrane [28]. None of these probes enters intact cells. Finally, two subpopulations necrotic spermatozoa were easily detected, early necrotic, spermatozoa stained both with Yo-Pro-1 and ethidium homodimer (emitting both green and red fluorescence), and late necrotic spermatozoa, cells stained only with ethidium homodimer (emitting red fluorescence).

\section{5.- Staining for detection of lipid peroxidation}

Lipid peroxidation (LPO) was measured using the probe BODIPY 581/591 $\mathrm{C}_{11}$ (Molecular Probes, Leiden, The Netherlands). A suspension of $2 \times 10^{6} / \mathrm{ml}$ spermatozoa was loaded with the probe at a final concentration of $2 \mu \mathrm{M}$. The spermatozoa were then incubated at $37^{\circ} \mathrm{C}$ for $30 \mathrm{~min}$, washed by centrifugation to remove the unbound probe, and analyzed using a flow cytometer. Positive controls were obtained after addition of $80 \mu \mathrm{M}$ ferrous sulfate to additional sperm suspensions [29].

\section{6.- Detection of active caspases 3,7 and 8}

The caspases FITC-DEVD-FMK (caspase 3 and 7) and FITC-LETD-FMK (caspase 8) in situ markers (Molecular Probes, Leiden, The Netherlands) were used to detect active caspases, 3, 7 and 8 in the spermatozoa. These cell permeable specific caspase inhibitor peptides are conjugated to fluorescein isothiocyanate (FITC) and binds covalently to active caspases serving as in situ markers for apoptosis. A sample of $5 \times 10^{6}$ freshly ejaculated or post-thawed spermatozoa were suspended in $1 \mathrm{~mL}$ of PBS, and -after adding one $\mu \mathrm{L}$ of FITC DEVD-FMK or FICT-LETD-FMK $(5 \mathrm{mM})$ - the suspensions were incubated at room temperature $\left(22-25^{\circ} \mathrm{C}\right)$ in the dark for 20 minutes. After incubation, the spermatozoa were washed with PBS, followed by the addition of $1 \mu \mathrm{L}$ of ethidium homodimer $(1.167 \mathrm{mM})$ (Molecular Probes Europe, Leiden, The Netherlands) to detect membrane damage. Flow cytometry and fluorescence microscopy were conducted within 10 minutes.

\section{7.- Evaluation of mitochondrial membrane potential ( $\Delta \Psi \mathrm{m})$}


The lipophilic cationic compound 5,5',6,6'-tetrachloro-1,1',3,3' tetraethylbenzymidazolyl carbocianyne iodine (JC-1, Molecular Probes Europe) has the unique ability to differentially label mitochondria with low and high membrane potential. In mitochondria with high membrane potential, JC-1 forms multimeric aggregates emitting in the high orange wavelength of $590 \mathrm{~nm}$, when excited at $488 \mathrm{~nm}$. At the same excitement wavelength (488 $\mathrm{nm}$ ), however, JC-1 forms monomers within mitochondria with low membrane potential, emitting in the green wavelength ( 525 to $530 \mathrm{~nm}$ ). For staining, a $3 \mathrm{mM}$ stock solution of JC-1 was prepared in DMSO. From each sperm suspension, $5 \times 10^{6}$ spermatozoa were placed in one $\mathrm{mL}$ of PBS and stained with $0.5 \mu \mathrm{L} \mathrm{JC}-1$ stock solution. The samples were incubated at $38^{\circ} \mathrm{C}$ in the dark for $40 \mathrm{~min}$ before flow cytometric analysis.

\section{8.- Fluorescence staining of actin filaments}

The protocol for fluorescence staining of actin filaments was modified after protocols previously published both for spermatozoa[30] and somatic cells[31]. Samples were washed by centrifugation at $800 \mathrm{~g}$ for 30 seconds, seminal plasma was removed and corresponding aliquots were resuspended in BWW and incubated up to 1 hour at $37^{\circ} \mathrm{C}$. Treatments were glycerol at $0 \%, 0.5 \%, 1.5 \%, 2.5 \%, 3.5 \%, 5 \%$ and a hyperosmotic $(900 \mathrm{mOsm} / \mathrm{Kg})$ and a hyposmotic $(75 \mathrm{mOsm} / \mathrm{Kg}$ ) control. Spermatozoa were then fixed in $4 \%$ formaldehyde in PBS for 15 minutes at room temperature and cells were washed twice in PBS (800g for 30 seconds), and permeabilized using A $0,2 \%(\mathrm{v} / \mathrm{v})$ Triton X-100 solution in PBS for 5 minutes at room temperature. After permeabilization cells were again washed in PBS, a blocking solution (5\% BSA in PBS) added, and cells further incubated for 30 minutes at room temperature. Finally, cells were washed in PBS and stained with $1 \mu \mathrm{M}$ fluorescein isothiocyanate (FICT) labeled phalloidin (Sigma St Louis Mo) (stock solution made in 1\% BSA (v/w) in PBS) and incubated for 60 minutes at room temperature in the dark. After incubation the cells were collected by centrifugation at $800 \mathrm{~g}$ for 30 seconds and resuspended in PBS.

\section{9.- Flow Cytometry}

Flow cytometric analyses were carried out with a Coulter EPICS XL (Coulter Corporation Inc., Miami, FL, USA) flow cytometer equipped with standard optics, an argon-ion laser (Cyonics, Coherent, Santa Clara, CA, USA) performing $15 \mathrm{~mW}$ at $488 \mathrm{~nm}$ and EXPO 2000 software. Subpopulations were divided by quadrants, and the frequency of each subpopulation was quantified. Non-sperm events (debris) were gated out based on the forward scatter and side scatter dot-plot by drawing a region enclosing the cell population of interest. Forward and sideways light scatter were recorded for a total of 10,000 events per sample. Samples were measured at flow rate of 200-300 cells/sec. Green fluorescence was detected in FL1(525 $\mathrm{nm}$ band pass filter) red fluorescence was detected in FL3 (620 nm band pass filter), and orange fluorescence in FL2 (570 $\mathrm{nm}$ band pass filter).

\subsection{0.- Confocal laser microscopy}

Sperm samples were observed under a spectral inverted confocal laser microscope (Bio Rad MRC 1024, Hercules CA USA). The localization of the FICT- labeled phalloidin emission was at $510 \mathrm{~nm}$. Samples were excited with an argon ion laser emitting at $488 \mathrm{~nm}$. 


\subsection{1.- Statistical analysis}

Comparisons were made using Multivariate analysis of variance using one-way ANOVA models followed by Tukey posttest, when data were distributed normally. When data were not normally distributed the non-parametric Mann-Whitney $U$-test was used to directly compare pairs of values. Analyses were performed using SPSS ver. 15.0 for Windows (SPSS Inc., Chicago, IL). Statistical significance was set at $p<0.05$.

\section{3.- RESULTS}

\section{1.- Effect of glycerol on sperm volume.}

Low concentrations of glycerol had no effect on sperm volume, but when spermatozoa were exposed to concentrations of glycerol of $2.5 \%$ a significant increase in the sperm volume was observed $(\mathrm{p}<0.05)$. At this concentration the osmolality of the solution was $670 \mathrm{mOsm} / \mathrm{Kg}$. After 1 hour of incubation cellular volume was also significantly increased by a concentration of $1.5 \%$ glycerol in the media (table 1 ).

\section{2.- Effect of glycerol on subtle sperm membrane changes and viability}

A significant decrease $(\mathrm{p}<0.05)$ in sperm membrane integrity was observed when spermatozoa were incubated in presence of $5 \%$ glycerol (table 2 ). The effect was already evident at the beginning of the incubation period. This impairment in the integrity of the membrane was due to an increase in the percentage of necrotic (ethidium + ) spermatozoa, since neither the percentages of early (YoPro+/Eth-) nor late apoptotic (YoPro+/Eth+) increased.

\section{3.- Lipid peroxidation}

Exposure of stallion spermatozoa to glycerol did not change the percentage of lipid peroxidation, thaw was low (below $2 \%$ ) in all the samples studied at any time of incubation (table 3).

\section{4.- Activation of caspases 3,7 and 8}

Since has been demonstrated that cryopreservation induces caspase activity[32], and in order to determine if this effect can be attributed to the intrinsic toxicity of glycerol or to osmotic stress, spermatozoa were incubated in presence of glycerol and also in a hypo and hyperosmotic solution. Glycerol did not induce the activation of any of the caspases studied. The only change observed in our study was a significant increase in the activation of caspase 8 and caspase 3 and 7 in dead (Ethidium + ) cells when spermatozoa were incubated at 900 $\mathrm{mOsm} / \mathrm{Kg}$ (table 4).

\section{5.- Effect of glycerol on mitochondrial membrane potential $(\Delta \Psi \mathrm{m})$}


Incubation of spermatozoa in glycerol supplemented BWW produced a significant increase in the percentage mitochondria showing low $\Delta \Psi \mathrm{m}$ when glycerol was present at $5 \%$ (table 5).

\section{6.- Effect of glycerol on sperm actin cytoskeleton}

Previous research has demonstrated that hypertonic shock induces a reorganization of the actin cytoskeleton[30] so we decided to study if glycerol may cause a similar effect. For this we incubated stallion spermatozoa in increasing concentrations of glycerol and also in hypotonic and hypertonic solutions. Glycerol resulted in a concentration dependent dramatic decrease in Actin-f, while hypertonocity resulted in a redistribution of Actin-f fluorescence towards the post-acrosomal region (Figure 1)

\section{4.- DISCUSSION}

In this study, we determined the direct effect of glycerol on the physiology of stallion spermatozoa, in order to characterize the toxic concentration and also to investigate potential mechanisms of sperm damage. The most dramatic effect of glycerol was a dramatic decrease in actin $\mathrm{f}$ starting at a concentration of $1.5 \%$. Glycerol was toxic to stallion spermatozoa when present at concentrations equal or greater than 3.5\%, being especially toxic for the sperm membranes. The osmolality of the solution containing 3.5\% glycerol was $670 \mathrm{mOsm} / \mathrm{Kg}$, this indicates that stallion spermatozoa are very sensitive to glycerol since human spermatozoa started to experience cellular damage when the osmolality of the solution containing this cryoprotectant was above $3000 \mathrm{mOsm} / \mathrm{Kg}[17]$.

Glycerol may induce cellular damage through two distinct mechanisms, either an osmotic effect and/or a biochemically $[19,20]$. The permeability of the sperm membrane to glycerol will control the osmotic damage, and glycerol is considered less permeable than other cryoprotectants [33]. To determine in our experiment whether or not the major damage induced by glycerol was of osmotic nature, we measured the osmolality of the solutions containing glycerol and the cellular volume of the spermatozoa incubated in each concentration of the cryoprotectant. Low concentrations of glycerol did not induce changes in sperm volume, but glycerol at $2.5 \%$ after 10 minutes and $1.5 \%$ after 60 minutes of incubation induced an increase of sperm volume. The osmolality of the solutions containing $1,5 \%$ and $2.5 \%$ glycerol were respectively 388 and $490 \mathrm{mOsm} / \mathrm{Kg}$ and thus instead an increase in cellular volume a slight decrease should have been expected if only the osmolality is took in account. This effect is explained by the ability of glycerol to retain water within the cell, the fact that glycerol at $2.5 \%$ only induced changes in volume after 1 hour of incubation can be related to the fact that glycerol does not reach an equilibrium immediately due to a relatively low permeability of the stallion spermatozoa to the CPA. Data from human spermatozoa indicates that once exposed to glycerol spermatozoa shrink because of dehydration and then increase in volume as the glycerol permeates and water concomitantly re-enters the cell [34]. One possible explanation for our findings is that human spermatozoa is very permeable to glycerol[16], so this changes in cellular volume occurs in a short period, while the more impermeable membrane of the stallion spermatozoa makes this process to occur much more slowly and thus causing more damage. It has been hypothesized that the actin cytoskeleton is damaged during cryopreservation[35, 36] and indirect evidence have been described in ram spermatozoa[37]. In order to further determine if glycerol may damage the sperm cytoskeleton the percentage of $\mathrm{F}$ actin was evaluated. In order to increase the permeability of 
the stallion spermatozoa to glycerol we incubated the cells at $37^{\circ} \mathrm{C}$ instead at room temperature, this approach helped to characterize the biochemical toxicity of glycerol that apparently was exerted over the actin cytoskeleton, through actin $\mathrm{f}$ depolymerization, while hyperosmolarity induced a redistribution of f-actin fluorescence in a similar way as previously described in monkey spermatozoa [30]. Probably the toxicity of glycerol is due to its action on the cytoskeleton; in addition to our findings two facts support this theory. First it has been suggested that the cytoskeleton acts as a cell volume sensor and also offers protection against the deleterious effect of excessive shrinkage[38], and has been proposed that the toxicity of glycerol for human erythrocytes is due to the fact that glycerol renders red cells susceptible to osmotic stress at thawing[39]. As indicated before glycerol induced cellular damage, since a significant decrease in the percentage of intact membranes was observed in samples incubated in presence of $5 \%$ glycerol, but also concentrations of glycerol of $3.5 \%$ resulted in a significant increase in the percentage of necrotic (ethidium + ) spermatozoa. The damage was not oxidative since lipid peroxidation was not affected by any of the concentrations of glycerol tested. The mitochondria of stallion spermatozoa were affected by incubation in presence of $5 \%$ glycerol after 1 hour of incubation, this may represent that glycerol diffuses slowly or a major resistance of these organelle to glycerol toxicity. Also this may explain the lack of lipid peroxidation in our experiment, but another possible explanation relies in the ability of glycerol to scavenge the hydroxyl radical[40]. The sperm mitochondria have been characterized as the main source of reactive oxygen species in the spermatozoa [41, 42], and also the sperm structures more sensitive to the damage induced by cryopreservation $[25,26$, 43-45], but glycerol toxicity does not seem to be a major factor involved in mitochondrial damage. Finally we studied the activity of caspases 3, 7 and 8, however none of the glycerol concentrations studied resulted in a significant increase in any of the caspases studied. Since cryopreservation [26, 46] induces activation of caspases, we also studied the effect of a hyperosmotic and a hyposmotic shock in caspase activation. Only exposition to high osmolality induced a significant increase in the percentage of dead (ethidium + ) spermatozoa showing caspase activity. Interestingly the osmotic shock induced a great increase of caspase $8+$ cells, this may indicate that the extrinsic pathway of apoptosis may be present in stallion spermatozoa. Recent data in somatic cells indicates that osmotic stress may induce caspase 8 activation[47]. Activation of caspase 8 occur during human sperm cryopreservation [48], but not in bovine sperm cryopreservation[49]. In view of our results the toxicity to glycerol explain some of the damages induced by cryopreservation, the toxicity induced by glycerol may be enhanced when the cryoprotectant is concentrated in the frozen state [11].

In sum, we studied the toxicity of glycerol to stallion spermatozoa, this cryoprotectant damages sperm membranes when is present at concentrations over $3.5 \%$, our results suggest that this damage is related to an osmotic effect but also is due to the intrinsic toxicity of glycerol upon the actin cytoskeleton that may compromise the capacity of the spermatozoa to cope with osmotic stress. In view of our results glycerol should be present in the extenders at a concentration not exceeding $2.5 \%$

\section{5.- References}

[1] Aurich J, Aurich C. Developments in European horse breeding and consequences for veterinarians in equine reproduction. Reprod Domest Anim. 2006;41:275-9.

[2] Allen WR. The development and application of the modern reproductive technologies to horse breeding. Reprod Domest Anim. 2005;40:310-29. 
[3] Bruemmer JE. Collection and freezing of epididymal stallion sperm. Vet Clin North Am Equine Pract. 2006;22:677-82.

[4] Loomis PR, Graham JK. Commercial semen freezing: individual male variation in cryosurvival and the response of stallion sperm to customized freezing protocols. Animal reproduction science. 2008;105:119-28.

[5] Mazur P, Leibo SP, Seidel GE, Jr. Cryopreservation of the germplasm of animals used in biological and medical research: importance, impact, status, and future directions. Biology of reproduction. 2008;78:2-12.

[6] Samper JC, Morris CA. Current methods for stallion semen cryopreservation: a survey. Theriogenology. 1998;49:895-903.

[7] Woods EJ, Benson JD, Agca Y, Critser JK. Fundamental cryobiology of reproductive cells and tissues. Cryobiology. 2004;48:146-56.

[8] Mazur P. Cryobiology: the freezing of biological systems. Science. 1970;168:939-49.

[9] Mazur P. Freezing of living cells: mechanisms and implications. Am J Physiol. 1984;247:C125-42.

[10] Mazur P, Kleinhans FW. Relationship between intracellular ice formation in oocytes of the mouse and Xenopus and the physical state of the external medium--a revisit. Cryobiology. 2008;56:22-7.

[11] Fahy GM. Cryoprotectant toxicity neutralization. Cryobiology. 2010;60:S45-53.

[12] Meryman HT. Cryoprotective agents. Cryobiology. 1971;8:173-83.

[13] Vidament M, Ecot P, Noue P, Bourgeois C, Magistrini M, Palmer E. Centrifugation and addition of glycerol at 22 degres $\mathrm{C}$ instead of 4 degrees $\mathrm{C}$ improve post-thaw motility and fertility of stallion spermatozoa. Theriogenology. 2000;54:907-19.

[14] Vidament M, Yvon JM, Couty I, Arnaud G, Nguekam-Feugang J, Noue P, et al. Advances in cryopreservation of stallion semen in modified INRA82. Animal reproduction science. 2001;68:201-18.

[15] Loomis PR, Amann RP, Squires EL, Pickett BW. Fertility of unfrozen and frozen stallion spermatozoa extended in EDTA-lactose-egg yolk and packaged in straws. Journal of animal science. 1983;56:687-93.

[16] Gao DY, Mazur P, Kleinhans FW, Watson PF, Noiles EE, Critser JK. Glycerol permeability of human spermatozoa and its activation energy. Cryobiology. 1992;29:657-67.

[17] Gao DY, Ashworth E, Watson PF, Kleinhans FW, Mazur P, Critser JK. Hyperosmotic tolerance of human spermatozoa: separate effects of glycerol, sodium chloride, and sucrose on spermolysis. Biology of reproduction. 1993;49:112-23.

[18] Ball BA, Vo A. Osmotic tolerance of equine spermatozoa and the effects of soluble cryoprotectants on equine sperm motility, viability, and mitochondrial membrane potential. Journal of andrology. 2001;22:1061-9.

[19] Fahy GM. The relevance of cryoprotectant "toxicity" to cryobiology. Cryobiology. 1986;23:1-13.

[20] Fahy GM, Levy DI, Ali SE. Some emerging principles underlying the physical properties, biological actions, and utility of vitrification solutions. Cryobiology. 1987;24:196213.

[21] Morris GJ, Faszer K, Green JE, Draper D, Grout BW, Fonseca F. Rapidly cooled horse spermatozoa: loss of viability is due to osmotic imbalance during thawing, not intracellular ice formation. Theriogenology. 2007;68:804-12.

[22] Fahy GM, Karow AM, Jr. Ultrastructure-function correlative studies for cardiac cryopreservation. V. Absence of a correlation between electrolyte toxicity and cryoinjury in the slowly frozen, cryoprotected rat heart. Cryobiology. 1977;14:418-27. 
[23] McLaughlin EA, Ford WC, Hull MG. The contribution of the toxicity of a glycerol-egg yolk-citrate cryopreservative to the decline in human sperm motility during cryopreservation. Journal of reproduction and fertility. 1992;95:749-54.

[24] Pena FJ, Saravia F, Johannisson A, Walgren M, Rodriguez-Martinez H. A new and simple method to evaluate early membrane changes in frozen-thawed boar spermatozoa. Int $\mathrm{J}$ Androl. 2005;28:107-14.

[25] Ortega Ferrusola C, Gonzalez Fernandez L, Morrell JM, Salazar Sandoval C, Macias Garcia B, Rodriguez-Martinez H, et al. Lipid peroxidation, assessed with BODIPY-C11, increases after cryopreservation of stallion spermatozoa, is stallion-dependent and is related to apoptotic-like changes. Reproduction. 2009;138:55-63.

[26] Ortega-Ferrusola C, Sotillo-Galan Y, Varela-Fernandez E, Gallardo-Bolanos JM, Muriel A, Gonzalez-Fernandez L, et al. Detection of "apoptosis-like" changes during the cryopreservation process in equine sperm. J Androl. 2008;29:213-21.

[27] Ormerod MG, Sun XM, Snowden RT, Davies R, Fearnhead H, Cohen GM. Increased membrane permeability of apoptotic thymocytes: a flow cytometric study. Cytometry. 1993;14:595-602.

[28] Idziorek T, Estaquier J, De Bels F, Ameisen JC. YOPRO-1 permits cytofluorometric analysis of programmed cell death (apoptosis) without interfering with cell viability. Journal of immunological methods. 1995;185:249-58.

[29] Aitken RJ, Wingate JK, De Iuliis GN, McLaughlin EA. Analysis of lipid peroxidation in human spermatozoa using BODIPY C11. Mol Hum Reprod. 2007;13:203-11.

[30] Correa LM, Thomas A, Meyers SA. The macaque sperm actin cytoskeleton reorganizes in response to osmotic stress and contributes to morphological defects and decreased motility. Biol Reprod. 2007;77:942-53.

[31] Redondo PC, Harper MT, Rosado JA, Sage SO. A role for cofilin in the activation of store-operated calcium entry by de novo conformational coupling in human platelets. Blood. 2006;107:973-9.

[32] Ball BA. Oxidative stress, osmotic stress and apoptosis: impacts on sperm function and preservation in the horse. Anim Reprod Sci. 2008;107:257-67.

[33] Glazar AI, Mullen SF, Liu J, Benson JD, Critser JK, Squires EL, et al. Osmotic tolerance limits and membrane permeability characteristics of stallion spermatozoa treated with cholesterol. Cryobiology. 2009;59:201-6.

[34] Du J, Kleinhans FW, Mazur P, Critser JK. Human spermatozoa glycerol permeability and activation energy determined by electron paramagnetic resonance. Biochimica et biophysica acta. 1994;1194:1-11.

[35] Watson PF. Recent developments and concepts in the cryopreservation of spermatozoa and the assessment of their post-thawing function. Reprod Fertil Dev. 1995;7:871-91.

[36] Watson PF. The causes of reduced fertility with cryopreserved semen. Anim Reprod Sci. 2000;60-61:481-92.

[37] Holt WV, North RD. Cryopreservation, actin localization and thermotropic phase transitions in ram spermatozoa. Journal of reproduction and fertility. 1991;91:451-61.

[38] Burg MB, Ferraris JD, Dmitrieva NI. Cellular response to hyperosmotic stresses. Physiol Rev. 2007;87:1441-74.

[39] Rall WF, Mazur P, Souzu H. Physical-chemical basis of the protection of slowly frozen human erythrocytes by glycerol. Biophysical journal. 1978;23:101-20.

[40] Miller JS, Cornwell DG. The role of cryoprotective agents as hydroxyl radical scavengers. Cryobiology. 1978;15:585-8. 
[41] Koppers AJ, De Iuliis GN, Finnie JM, McLaughlin EA, Aitken RJ. Significance of mitochondrial reactive oxygen species in the generation of oxidative stress in spermatozoa. J Clin Endocrinol Metab. 2008;93:3199-207.

[42] Koppers AJ, Garg ML, Aitken RJ. Stimulation of mitochondrial reactive oxygen species production by unesterified, unsaturated fatty acids in defective human spermatozoa. Free Radic Biol Med. 2010;48:112-9.

[43] Pena FJ, Rodriguez Martinez H, Tapia JA, Ortega Ferrusola C, Gonzalez Fernandez L, Macias Garcia B. Mitochondria in mammalian sperm physiology and pathology: a review. Reprod Domest Anim. 2009;44:345-9.

[44] Pena FJ, Johannisson A, Wallgren M, Rodriguez Martinez H. Antioxidant supplementation in vitro improves boar sperm motility and mitochondrial membrane potential after cryopreservation of different fractions of the ejaculate. Anim Reprod Sci. 2003;78:8598.

[45] Pena FJ, Johannisson A, Wallgren M, Rodriguez-Martinez H. Assessment of fresh and frozen-thawed boar semen using an Annexin-V assay: a new method of evaluating sperm membrane integrity. Theriogenology. 2003;60:677-89.

[46] Ortega-Ferrusola C, Garcia BM, Gallardo-Bolanos JM, Gonzalez-Fernandez L, Rodriguez-Martinez H, Tapia JA, et al. Apoptotic markers can be used to forecast the freezeability of stallion spermatozoa. Anim Reprod Sci. 2009;114:393-403.

[47] Xia Y, Wang J, Liu TJ, Yung WK, Hunter T, Lu Z. c-Jun downregulation by HDAC3dependent transcriptional repression promotes osmotic stress-induced cell apoptosis. Molecular cell. 2007;25:219-32.

[48] Wundrich K, Paasch U, Leicht M, Glander HJ. Activation of caspases in human spermatozoa during cryopreservation--an immunoblot study. Cell and tissue banking. 2006;7:81-90.

[49] Martin G, Cagnon N, Sabido O, Sion B, Grizard G, Durand P, et al. Kinetics of occurrence of some features of apoptosis during the cryopreservation process of bovine spermatozoa. Human reproduction. 2007;22:380-8. 
Table1.- Cellular volume $\mathrm{mm}^{3}($ mean $\pm \mathrm{SD})$ of stallion spermatozoa incubated in BWW media supplemented with different concentrations of glycerol. The osmolality of each solution was respectively 388, 492, 670, 750 and $1300 \mathrm{mOsm} / \mathrm{Kg}$. T0, measurement after 10 minutes of incubation, T1, measurement after 60 minutes of incubation at $37^{\circ} \mathrm{C}$

\begin{tabular}{lllllll}
\hline Glycerol & \multicolumn{5}{l}{} \\
\hline & $0 \%$ & $0.5 \%$ & $1.5 \%$ & $2.5 \%$ & $3.5 \%$ & $5 \%$ \\
T0 & $21.3 \pm 2.30^{\mathrm{a}}$ & $21.9 \pm 2.94$ & $21.9 \pm 2.37$ & $23.6 \pm 2.65^{\mathrm{b}}$ & $23.5 \pm 2.63$ & $22.0 \pm 2.60$ \\
$\mathrm{~T} 1$ & $22.1 \pm 3.45^{\mathrm{a}}$ & $23.1 \pm 3.56$ & $24.6 \pm 4.18^{\mathrm{b}}$ & $24.8 \pm 3.57^{\mathrm{b}}$ & $24.3 \pm 2.70$ & $24.5 \pm 2.50$ \\
\hline
\end{tabular}

$a-b$ within a row values differ statistically $p<0.05$

Table 2.- Membrane integrity (mean $\pm \mathrm{SE}$ ) and early membrane changes of stallion spermatozoa incubated in BWW media supplemented with different concentrations of glycerol. The osmolality of each solution was respectively 388, 492, 670, 750 and 1300 $\mathrm{mOSm} / \mathrm{Kg}$. T0, measurement after 10 minutes of incubation, T1, measurement after 60 minutes of incubation at $37^{\circ} \mathrm{C}$

\begin{tabular}{lllllll}
\hline Glycerol & & & & \\
\hline & $0 \%$ & $0.5 \%$ & $1.5 \%$ & $2.5 \%$ & $3.5 \%$ & $5 \%$ \\
Live & & & & & \\
T0 & $64.8 \pm 6.44^{\mathrm{a}}$ & $62.9 \pm 5.51^{\mathrm{a}}$ & $61.6 \pm 9.86^{\mathrm{a}}$ & $61.7 \pm 7.88^{\mathrm{a}}$ & $58.4 \pm 8.49^{\mathrm{a}}$ & $52.2 \pm 12.50^{\mathrm{b}}$ \\
T1 & $62.8 \pm 7.78^{\mathrm{a}}$ & $61.6 \pm 9.86^{\mathrm{a}}$ & $61.4 \pm 10.73^{\mathrm{a}}$ & $58.5 \pm 8.49^{\mathrm{a}}$ & $58.2 \pm 11.60^{\mathrm{a}}$ & $49.9 \pm 11.26^{\mathrm{b}}$ \\
YoPro+ & & & & & & \\
T0 & $5.5 \pm 6.79$ & $4.3 \pm 3.19$ & $4.5 \pm 4.92$ & $3.6 \pm 3.81$ & $3.0 \pm 2.47$ & $4.7 \pm 5.72$ \\
T1 & $5.0 \pm 6.30$ & $2.3 \pm 2.48$ & $2.6 \pm 2.57$ & $3.4 \pm 3.38$ & $3.3 \pm 2.84$ & $3.1 \pm 2.83$ \\
YoPro+Eth+ & & & & & & \\
T0 & $5.9 \pm 3.87$ & $4.8 \pm 2.30$ & $4.7 \pm 3.27$ & $4.7 \pm 2.92$ & $4.3 \pm 3.15$ & $5.5 \pm 4.56$ \\
T1 & $5.9 \pm 5.46$ & $3.5 \pm 2.38$ & $6.2 \pm 10.11$ & $4.6 \pm 3.39$ & $4.6 \pm 3.22$ & $4.5 \pm 2.90$ \\
Eth+ & & & & & & \\
T0 & $23.7 \pm 6.51^{\mathrm{a}}$ & $27.8 \pm 4.83^{\mathrm{a}, \mathrm{c}}$ & $27.3 \pm 9.39^{\mathrm{a}}$ & $29.9 \pm 4.83^{\mathrm{a}, \mathrm{b}, \mathrm{c}}$ & $34.1 \pm 7.47^{\mathrm{b}, \mathrm{c}}$ & $37.6 \pm 11.43^{\mathrm{b}}$ \\
T1 & $26.3 \pm 8.06^{\mathrm{a}}$ & $32.5 \pm 7.92^{\mathrm{a}}$ & $29.7 \pm 10.31^{\mathrm{a}}$ & $34.6 \pm 7.85^{\mathrm{a}, \mathrm{b}}$ & $33.9 \pm 8.69^{\mathrm{b}}$ & $42.5 \pm 10.79^{\mathrm{b}}$ \\
& & & & & & \\
\hline
\end{tabular}

within a row values with different superscripts differ statistically a-c $p<0.05$ 
Table 3.- Lipid peroxidation (mean \pm SE) $(\mathrm{LPO})$ of stallion spermatozoa incubated in BWW media supplemented with different concentrations of glycerol. The osmolality of each solution was respectively $388,492,670,750$ and $1300 \mathrm{mOSm} / \mathrm{Kg}$. T0, measurement after 10 minutes of incubation, T1, measurement after 60 minutes of incubation at $37^{\circ} \mathrm{C}$

\begin{tabular}{|c|c|c|c|c|c|c|}
\hline \multicolumn{7}{|c|}{ Glycerol } \\
\hline & $0 \%$ & $0.5 \%$ & $1.5 \%$ & $2.5 \%$ & $3.5 \%$ & $5 \%$ \\
\hline LPO-TO & $1.7 \pm 0.33$ & $1.0 \pm 0.33$ & $1.2 \pm 0.33$ & $0.8 \pm 0.33$ & $0.6 \pm 0.33$ & $0.8 \pm 0.33$ \\
\hline LPO-T1 & $2.0 \pm 0.33$ & $1.2 \pm 0.33$ & $1.1 \pm 0.33$ & $1.1 \pm 0.33$ & $1.0 \pm 0.33$ & $1.3 \pm 0.33$ \\
\hline
\end{tabular}

Table 4.- caspase 3, 7 and 8 activation (means \pm SD) of stallion spermatozoa incubated for 1 hour at $37^{\circ} \mathrm{C}$ in BWW media supplemented with different concentrations of glycerol. The osmolality of each solution was respectively 388, 492, 670, 750 and $1300 \mathrm{mOSm} / \mathrm{Kg}$. A hyposmotic control $(75 \mathrm{mOsm} / \mathrm{Kg})$ and an hypertonic control $(900 \mathrm{mOsm} / \mathrm{Kg})$ were also included.

\begin{tabular}{|l|l|l|}
\hline Treatment & Caspase 8+ dead cells & Caspase $\mathbf{3}$ and 7+ dead cells \\
\hline Control & $41.9 \pm 12.81^{\mathrm{a}}$ & $21.7 \pm 12.64^{\mathrm{a}, \mathrm{b}}$ \\
\hline $\mathbf{0 . 5 \%}$ Glycerol & $33.3 \pm 15.59^{\mathrm{a}}$ & $26.4 \pm 22.56^{\mathrm{a}, \mathrm{b}}$ \\
\hline $\mathbf{1 . 5 \%}$ Glycerol & $42.1 \pm 14.87^{\mathrm{a}}$ & $25.9 \pm 15.89^{\mathrm{a}, \mathrm{b}}$ \\
\hline $\mathbf{2 . 5 \%}$ Glycerol & $37.4 \pm 18.40^{\mathrm{a}}$ & $23.6 \pm 10.47^{\mathrm{a}, \mathrm{b}}$ \\
\hline $\mathbf{3 . 5 \%}$ Glycerol & $30.1 \pm 15.71^{\mathrm{a}}$ & $37.8 \pm 14.08^{\mathrm{a}, \mathrm{b}}$ \\
\hline $\mathbf{5 \%}$ Glycerol & $40.6 \pm 13.98^{\mathrm{a}}$ & $15.71 \pm 17.50^{\mathrm{b}}$ \\
\hline $\mathbf{7 5} \mathbf{~ \mathbf { O s m } / \mathbf { K g }}$ & $47.8 \pm 8.74^{\mathrm{a}}$ & $18.2 \pm 16.33^{\mathrm{b}}$ \\
\hline $\mathbf{9 0 0} \mathbf{~ \mathbf { O s m } / \mathbf { K g }}$ & $68.0 \pm 17.88^{\mathrm{b}}$ & $41.5 \pm 23.52^{\mathrm{a}}$ \\
\hline
\end{tabular}

within a row values with different superscripts differ statistically a-c $\mathrm{p}<0.01$ 
Table 5. Mitochondrial membrane potential $(\Delta \Psi \mathrm{m})$ of stallion spermatozoa incubated in BWW media supplemented with different concentrations of glycerol. The osmolality of each solution was respectively 388, 492, 670, 750 and $1300 \mathrm{mOSm} / \mathrm{Kg}$. T0, measurement after 10 minutes of incubation, T1, measurement after 60 minutes of incubation at $37^{\circ} \mathrm{C}$

\begin{tabular}{|c|c|c|c|c|c|c|}
\hline \multicolumn{7}{|l|}{ Glycerol } \\
\hline & $0 \%$ & $0.5 \%$ & $1.5 \%$ & $2.5 \%$ & $3.5 \%$ & $5 \%$ \\
\hline \multicolumn{7}{|l|}{ High } \\
\hline \multicolumn{7}{|l|}{$\Delta \Psi_{\mathrm{m}}$} \\
\hline T0 & $33.2 \pm 12.55$ & $31.7 \pm 12.41$ & $33.2 \pm 13.29$ & $36.2 \pm 12.67^{\mathrm{a}}$ & $33.0 \pm 9.33$ & $26.2 \pm 11.99^{b}$ \\
\hline $\mathrm{T} 1$ & $27.2 \pm 13.57$ & $23.6 \pm 11.03$ & $27.1 \pm 14.89$ & $30.1 \pm 13.59$ & $27.9 \pm 12.17$ & $22.2 \pm 10.89$ \\
\hline \multicolumn{7}{|l|}{ High and } \\
\hline \multicolumn{7}{|l|}{ Low $\Delta \Psi \mathrm{m}$} \\
\hline T0 & $40.9 \pm 14.82$ & $41.9 \pm 15.07$ & $39.4 \pm 15.49$ & $37.0 \pm 14.85$ & $36.6 \pm 12.16$ & $35.5 \pm 12.89$ \\
\hline $\mathrm{T} 1$ & $40.5 \pm 15.56$ & $43.2 \pm 13.7$ & $40.5 \pm 16.61$ & $38.2 \pm 16.89$ & $38.1 \pm 13.59$ & $36.8 \pm 11.49$ \\
\hline \multicolumn{7}{|l|}{ Low } \\
\hline$\Delta \Psi \mathrm{m}$ & & & & & & \\
\hline T0 & $25.3 \pm 5.60^{\mathrm{a}}$ & $25.9 \pm 5.13^{\mathrm{a}}$ & $26.9 \pm 7.33^{\mathrm{a}}$ & $26.4 \pm 7.22^{\mathrm{a}}$ & $30.1 \pm 7.57^{\mathrm{a}}$ & $37.7 \pm 11.60^{b}$ \\
\hline $\mathrm{T} 1$ & $31.9 \pm 8.01^{\mathrm{a}}$ & $32.3 \pm 8.20^{\mathrm{a}}$ & $32.3 \pm 8.19^{\mathrm{a}}$ & $32.1 \pm 9.57^{\mathrm{a}}$ & $31.3 \pm 7.94^{\mathrm{a}}$ & $40.5 \pm 11.94^{b}$ \\
\hline
\end{tabular}


Figure 1.- Falloidin-FICT fluorescence (actin-F) of stallion spermatozoa incubated for 1 hour at $37^{\circ} \mathrm{C}$ in BWW media supplemented with different concentrations of glycerol $(0 \%, 0.5 \%$ $1.5 \%, 2.5 \%, 3.5 \%, 5 \%)$. A hyposmotic control $(75 \mathrm{mOsm} / \mathrm{Kg})$ and an hypertonic control (900 $\mathrm{mOsm} / \mathrm{Kg}$ ) were also included. Hyperosmolality induced the redistribution of $\mathrm{F}$-actin to the postacrosomal region (A isosmotic 0\% glycerol control), while glycerol at concentrations equal or greater than $1.5 \%$ induced $\mathrm{f}$ actin depolymerization (D $0.5 \%$ glycerol, $\mathbf{E} 1.5 \%$ glycerol $\mathbf{F}$ transmission image combined with laser illumination 1,5\% glycerol). Images are representative of 8 identical experiments 
A

B

C

D

E

F

$\bullet$ 